\title{
New Leadership Model for Family Physicians in the Eastern Mediterranean Region: A Pilot Study Across Selected Countries
}

Rawaf S ${ }^{3 *}$, Qidwai W'2, Khoja TAM1, Nanji K², Kurashi NY ${ }^{4}$, Alnasir $F^{5}$, Al Shafaee MA ${ }^{6}$, Al Shetti $\mathrm{M}^{7}$, Bashir $\mathbf{M}^{8}$, Saad NES ${ }^{9}$, Alkaisi $\mathrm{S}^{10}$, Halasa W $^{11}$ Al-Duwaisan $\mathrm{H}^{12}$, Al-Ali $\mathrm{A}^{13}$, Farahat TM${ }^{14}$, Tarawneh $M^{15}$, Khathami $A^{16}$, Abutiheen $A^{17}$, Iqbal Azam SI ${ }^{18}$, Swaka $A^{3}$

${ }^{1}$ Hon Professor, Department of Primary Care and Public Health, Imperial College London, UK, Secretary General of Arab Hospital Federation

${ }^{2}$ Department of Family Medicine, Aga Khan University, Karachi, Pakistan

3Professor of Public Health, Director, WHO Collaborating Centre, Department of Primary Care and Public Health, School of Public Health, Faculty of Medicine, Imperial College London, UK

${ }^{4}$ University of Dammam, Saudi Arabia

${ }^{5}$ Department of Family \& Community Medicine, Arabian Gulf University, Bahrain

Vice Dean for Clinical Affairs, Oman Medical College, Sultanate of Oman

${ }^{7}$ Family Physician, Bahrain

${ }^{8}$ Department of Family Medicine, King Faisal Specialist Hospital and Research Centre, J eddah, Saudi Arabia ${ }^{9}$ Department of Family Medicine, Cairo University, Egypt ${ }^{10}$ Associate Professor of Community and Family Medicine, Senior Consultant Family Physician, Dubai

${ }^{11}$ Family Physician, Amman, J ordan

${ }^{12} \mathrm{Head}$ of the Primary Health Care Faculty at the Kuwait Institution for Medical Specialization

${ }^{13}$ Assistant Program Director in Family Medicine Residency Program-Qatar

${ }^{14}$ Chair Person of Egyptian Family Medicine Association and Faculty of Medicine, Menoufiya University, Shebin

El-Kom, Menoufia, Egypt

${ }^{15}$ WONCA EMR President

${ }^{16}$ Primary Health Care, Saudi Arabia

${ }^{17}$ Head of Family \& Community Med. Dept. \Karbala

University-, Iraq

${ }^{18}$ Community Health Sciences, Aga Khan University,

Karachi

*Corresponding author: Salman Rawaf, Professor of Public Health, Director, WHO Collaborating Centre, Department of Primary Care and Public Health, School of Public Health, Faculty of Medicine, Imperial College London, UK

Received: January 01, 2017; Accepted: J anuary 25, 2017; Published: J anuary 27, 2017

\section{Introduction}

The health of people living in the East Mediterranean Region (EMR) has substantially improved over the past decades. This improvement has been variable across different countries of the

\begin{abstract}
Background: Family Medicine is growing rapidly across the Eastern Mediterranean Region. However, it needs support in terms of overall health system development. This will require strong leadership in family medicine to implement the change required to improve current conditions.
\end{abstract}

Objective: To collect data that will support the development of a leadership program for the future family physicians in the region.

Methods: A cross-sectional study was conducted from July 2016 to September 2016 in eight countries of the Eastern Mediterranean Region, (Bahrain, Egypt, Iraq, Jordan, Kuwait, Qatar, Pakistan, and Saudi Arabia). These countries were selected to obtain perceptions of Family Physicians (FPs) regarding the current leadership model and to explore the need for a new future innovative model in Family Medicine (FM) across the region.

Results: The information of 68 family physicians was included in the final analysis. The majority of the FPs was females as compared to males $(71 \%$ vs. 29\%). Forty-four percent of the FPs had 10 to 19 years of experience. Almost all of the FPs (96\%) had completed some training in family medicine after graduation. About three fifths of the FPs had completed postgraduate qualifications and out of those, $64 \%$ had passed Board or Membership Examinations. Twenty-one percent of them are currently in a leadership role and $45 \%$ who were not in any leadership role responded that the current situation of FM in their country is poor. All of the leaders believed that it is important to develop strong leadership in FM to take the specialty forward. Almost similar proportions (67\% and $64 \%$ ) of leaders and non-leaders thought that establishing regional associations would enhance the FM practice model. Approximately two thirds of leaders (67\%) responded that the current role of decision makers in the Ministry of Health $(\mathrm{MOH})$ regarding capacity building in FM is not effective. The majority of the FPs (54\% and 38\%) considers that the existing postgraduate curriculum does not address leadership skill development in FM. Eighty-eight percent of the FPs both from leadership and non-leadership groups agreed that academic institutions and practicing FPs can play an effective leadership role in taking FM forward.

Conclusion: The Family Medicine specialty will have to develop leadership capabilities in line with today's fast-moving changes in healthcare for it to obtain the due recognition in the healthcare delivery system.

Keywords: Family Medicine; Family Physician; Family Practice; Leadership; Health System
J Fam Med - Volume 4 Issue 2 - 2017

ISSN : 2380-0658 | www.austinpublishinggroup.com

Swaka et al. (C) All rights are reserved
Citation: Rawaf S, Qidwai W, Khoja TAM, Nanji K, Kurashi NY and Alnasir F, et al. New Leadership Model for Family Physicians in the Eastern Mediterranean Region: A Pilot Study Across Selected Countries. J Fam Med. 2017; 4(2): 1107 region, based on the effective utilization of available resources [1]. Managing healthcare needs requires efficient and effective responses to new emerging challenges of rising patient expectations, ageing population, financial constraints, high healthcare costs, emerging diseases, equity issues, accessibility, and leadership of health systems 
in order to meet the expectations and survive current unfavorable situations $[2,3]$.

Scientific evidence supports the need for doctors to be more involved in managing health services $[3,4]$, which lead to better outcomes, greater ease of use, lower cost, and more social justice in health status [5]. A need has been established to strengthen health systems in general, but particularly primary care, as both require strong and effective leadership at all levels [6]. It is crucial to the future of the EMR health systems that family medicine physicians take a leadership role in advanced primary care practices and evolving health systems, as well as for doctors to consider themselves leaders in constructively addressing these challenges [2-5].

A leader is an individual who can demonstrate behaviors to favorably influence the attitudes and behaviors of others. Effective leaders in health services emphasize continually that safe, high quality, and compassionate care is the top priority. They ensure that the voice of patients is consistently heard at every level, and that patient experience, concerns, needs, and feedback (positive and negative) are consistently attended to [7].

Family medicine (FM) is a frontline specialty and is considered mandatory for effective health service delivery. Strong leadership in the specialty of family medicine is required to bring about desirable change in health and healthcare delivery across the region [8].

Effective leadership is one of the most critical and valued assets for successful family practice and for the discipline as a whole. Leadership positions pose great challenges and offer extraordinary rewards. It is well recognized that we need to discover, educate, and support our family medicine specialistsin playing a vital role in reshaping health service delivery, education, and research in the context of New Leadership Model for family physicians in the Eastern Mediterranean Region. The central question is how this goal can be achieved [9].

Among several factors, leadership failure to a certain extent, at the level of health service providers, could be a reason thathas prevented favorable change in service delivery [10] across the region. A lack of focus on leadership development exists in undergraduate, postgraduate, and continuing professional development programs for all healthcare providers [11,12]. By virtue of their focused professional training, health professionals become more technical in their approach, with less flexibility and adaptability including less focus on negotiation and communication skills. By training family physicians to be highly effective leaders, they could help implement favorable change in the overall health system with positive healthrelated outcomes in the region $[13,14]$.

Issues confronting the health profession are best understood by healthcare providers. If healthcare delivery related decisions are made outside the healthcare profession, health related outcomes are unlikely to improve. Politicians and bureaucrats are frequently the decision makers, while the actual healthcare providers tend not to be consulted because they are considered to lack effective managerial and leadership skills. Within the healthcare providers, family physicians are often left out of the decision-making process because they lack effective leadership skills, resulting in a tilt towards hospitalbased secondary care at the expense of community-based primary care service. These results not only in higher costs but also less than optimum health-related outcomes [15]. With the rapid advances and transformation of health and healthcare services, it is imperative that family medicine develops an effective leadership model that prepares future leadership in family medicine to tackle challenges of which this specialty is likely to encounter in future [16].

The future of family medicine hinges, in part, on having great and plentiful leaders in all areas of the discipline, working in an effective and integrated strategy with other family physicians and health professionals across the region. It is believed that efforts to train future leaders hold a key to the discipline's growth [9].

In the current leadership model and in most of our health systems, Family Physicians (FPs) are not being given their due recognition in healthcare delivery, taking back-seat roles, having less influence on health system development and with a less proactive role. This unfavorable situation needs to change, bringing it parallel with developed countries where family physicians are leading the healthsystems. It is linked to the way in which the systems are organized and led by primary care [16].

We identified a need to conduct a study in the EMR, enabling us to collect data in support of developing a leadership model for the family physician. It is expected that such a model will help in developing family physician leaders, enabling them to implement change in the overall health care delivery system and favorably impact health-related outcomes in the region.

\section{Methods}

\section{Study design \& setting}

A cross-sectional study was conducted from July 2016 to September 2016 across eight countries of the EMR (Bahrain, Egypt, Iraq, Jordan, Kuwait, Qatar, Pakistan and Saudi Arabia): EMR countries that have a population of close to 600 million. These countries were selected to obtain perceptions of Family Physicians regarding current leadership models and the need for a new, innovative model in Family Medicine across the EMR.

\section{Selection of participants}

FPs currently practicing in any country of the EMR were informed and invited to participate in the study by e-mail. Those who gave consent to participate were then sent a study questionnaire. The FPs was requested to complete and return the questionnaire within a month. Reminder e-mails were sent weekly to the FPs who had agreed to participate in the study.

\section{Ethical considerations}

Written informed consent was taken from all the FPs after informing them about the study protocol. The study was in compliance with the Declaration of Helsinki and the departmental research committee of the Aga Khan University, who reviewed and approved the study. Moreover, personal identifiers were not used at any point during data analysis or preparation of the manuscript.

\section{Study questionnaire}

After thorough search of literature and expert suggestions, a questionnaire was developed based on the need for a new leadership model in EMR Family Medicine and was prepared in English. The 
Table 1: Baseline characteristics of Family Physicians in the EMR ( $n=68)$.

\begin{tabular}{|c|c|c|}
\hline \multicolumn{1}{|c|}{ Variables } & Number & $\%$ \\
\hline Age Group & \multicolumn{2}{|c|}{} \\
\hline 25-34 years & 21 & 31 \\
\hline 35-44 years & 34 & 50 \\
\hline 45-54 years & 7 & 10 \\
\hline $55-59$ years & 4 & 6 \\
\hline$\geq 60$ years & 2 & 3 \\
\hline
\end{tabular}

\section{Gender}

\begin{tabular}{|c|c|c|}
\hline Male & 20 & 29 \\
\hline Female & 48 & 71 \\
\hline Internship after graduation & \multicolumn{2}{|l|}{} \\
\hline Yes & 65 & 96 \\
\hline No & 03 & 4 \\
\hline
\end{tabular}

\section{Postgraduate Training}

\begin{tabular}{|c|c|c|}
\hline Yes & 60 & 88 \\
\hline No & 08 & 12 \\
\hline Specialization $(\boldsymbol{n}=\mathbf{6 0})$ & 53 & 88 \\
\hline Family Medicine & 07 & 12 \\
\hline Others & & \\
\hline
\end{tabular}

\section{Postgraduate Qualification ( $n=60$ )}

\begin{tabular}{|c|c|c|}
\hline Diploma & 11 & 18 \\
\hline Master's Degree & 11 & 18 \\
\hline Board/Membership Exam & 38 & 64 \\
\hline
\end{tabular}

\section{Where $(n=60)$}

\begin{tabular}{|c|c|c|}
\hline In EMR & 52 & 87 \\
\hline Outside EMR & 08 & 13 \\
\hline
\end{tabular}

\section{Years of practice}

\begin{tabular}{|c|c|c|}
\hline$<5$ years & 8 & 12 \\
\hline $5-9$ years & 18 & 26 \\
\hline $10-19$ years & 30 & 44 \\
\hline $20-29$ years & 8 & 12 \\
\hline$\geq 30$ years & 4 & 6 \\
\hline Current Working Position & 9 & \\
\hline FP independent practice & 11 & 13 \\
\hline FP practice in private hospitals & 29 & 43 \\
\hline FP in government job & 19 & 28 \\
\hline University position & & \\
\hline
\end{tabular}

\begin{tabular}{|c|c|c|}
\hline Bahrain & 02 & 3 \\
\hline Egypt & 04 & 5 \\
\hline Iraq & 18 & 26 \\
\hline Jordan & 06 & 9 \\
\hline Kuwait & 8 & 12 \\
\hline Saudi Arabia & 4 & 6 \\
\hline Pakistan & 15 & 22 \\
\hline Qatar & 01 & 1 \\
\hline Other countries & 11 & 16 \\
\hline
\end{tabular}

questionnaire was piloted on four FPs and any ambiguities found were removed. The questionnaire was composed of two sections: demographic details of the FPs and questions about perceptions of
FPs regarding the current leadership role of FM in the EMR and characteristics of a new leadership model.

\section{Statistical analysis}

Data was entered and analyzed using SPSS version 19.0. Frequencies and proportions were reported for all categorical variables such as age, gender, years of practice, postgraduate qualification, etc. Means and standard deviations were calculated for the different leadership models. Pearson's chi-square test and T-test for two independent samples were used to compare the perceptions of FPs currently working on a leadership position and those who are not. Throughout the analysis, a $\mathrm{P}$ value of $<0.05$ was considered statistically significant.

\section{Results}

Sixty-eight FPs were included in the study; half of the participants were between the ages of 35 and 44, while only three percent of the FPs was over 60 years of age. The majority of the FPs was females as compared to males ( $71 \%$ vs. 29\%). Forty-four percent of the FPs had 10 to 19 years of experience. Almost all the FPs (96\%) had completed some form of training after graduation. About three fifths of the FPs had completed postgraduate qualifications and of those, $64 \%$ had passed Board or Membership Examinations following the completion of their training. Amongst the postgraduate FPs, the majority (88\%) specialized in Family Medicine and $43 \%$ worked in academic departments of family medicine (Table 1 ).

Twenty-one percent of the FPs was in a leadership role, while the $45 \%$ unaffiliated with a leadership role or post responded that the current situation of FM in their country is inadequate. All of the leaders believed that developing leadership in FM is important for improvement. An almost similar proportion (67\% and $64 \%)$ of leaders and non-leaders thought that establishing regional associations would enhance a FM practice model. Approximately two thirds of the leaders (67\%) responded that the current role of decision makers in the Ministry of Health regarding capacity building in FM is not effective. The majority of the FPs (54\% and 38\%) considers that the existing postgraduate curriculum does not address leadership skill development in FM. Of both the leadership and the non-leadership FP groups, $88 \%$ agreed that both academic institutions and practicing FPs could play an effective leadership role in enhancing the status of the specialty (Table 2).

Table 3 depicts recommendations of participating FPs regarding different leadership models in the EMR. The highest mean scores were obtained for a proactive model (FP leaders: mean $8.4+1.8$, FPs: $7.7+2.5)$ followed by academic and team leadership models. The lowest scores (FP leaders: mean 1.95+1.8, FPs: 2.15+2.1) were obtained when FPs were asked if they feel no leadership model is required to take FM forward.

Table 4 presents FP's perceptions of skills required for effective leadership for FM in EMR. Most of the FPs felt that communication skills are necessary, followed by planning and organizational skills. Only $8 \%$ of the FPs in current leadership positions and $64 \%$ belonging to the non-leadership group thought that language skills are important for an effective leader. About 25\% in current leadership positions said that marketing skills are required for effective leaders while slightly over three-fifths (61\%) of the FPs recommended 
Table 2: Perceptions of Family Physicians regarding effective leadership in FM in the EMR.

\begin{tabular}{|c|c|c|c|c|}
\hline Questions & Code & $\begin{array}{l}\text { In leadership } \\
\text { position } \\
n=24\end{array}$ & $\begin{array}{l}\text { Not in leadership } \\
\text { position } \\
n=44\end{array}$ & p-value \\
\hline \multirow{4}{*}{ Current situation of family medicine in your country } & \multirow{4}{*}{$\begin{array}{l}\text { Excellent } \\
\text { Good } \\
\text { Bad } \\
\text { In Crisis }\end{array}$} & 6 & $2(4)$ & \multirow{4}{*}{$\$ 0.04$} \\
\hline & & 10 & $16(36)$ & \\
\hline & & 5 & $20(45)$ & \\
\hline & & 3 & $6(14)$ & \\
\hline \multirow{2}{*}{ Leadership development in family medicine is important for pushing family medicine forward } & \multirow{2}{*}{$\begin{array}{l}\text { Yes } \\
\text { No }\end{array}$} & 24 & 36 & \multirow[b]{2}{*}{-} \\
\hline & & --- & 8 & \\
\hline \multirow{3}{*}{ Family physicians currently have a leadership position in healthcare } & \multirow{3}{*}{$\begin{array}{l}\text { Yes } \\
\text { No } \\
\text { May be }\end{array}$} & 13 & 13 & \multirow{3}{*}{0.10} \\
\hline & & 6 & 21 & \\
\hline & & 5 & 10 & \\
\hline \multirow{3}{*}{$\begin{array}{l}\text { The role played currently by family medicine leadership is effective in bringing a favorable } \\
\text { change in the EMR }\end{array}$} & \multirow{3}{*}{$\begin{array}{l}\text { Yes } \\
\text { No } \\
\text { May be }\end{array}$} & 12 & 11 & \multirow{3}{*}{0.13} \\
\hline & & 5 & 16 & \\
\hline & & 7 & 17 & \\
\hline \multirow{3}{*}{$\begin{array}{l}\text { Establishment of regional/sub-regional associations will enhance FM practice and leadership } \\
\text { in your country }\end{array}$} & Too much & 16 & 28 & \multirow{3}{*}{$\$ 0.85$} \\
\hline & Not at all & 4 & 10 & \\
\hline & Not so much & 4 & 6 & \\
\hline \multirow{3}{*}{$\begin{array}{l}\text { Current role of senior decision makers in the Ministry of Health regarding capacity building in } \\
\text { family medicine practice in your country }\end{array}$} & Very effective & 2 & 2 & \multirow{3}{*}{$\$ 0.87$} \\
\hline & Just effective & 6 & 8 & \\
\hline & Not effective & 16 & 34 & \\
\hline \multirow{2}{*}{$\begin{array}{l}\text { How do you score collaboration with the various international centers of excellence in support } \\
\text { of leadership development in FM? }\end{array}$} & $\begin{array}{l}\text { Highly } \\
\text { important }\end{array}$ & 17 & 31 & \multirow{2}{*}{0.75} \\
\hline & Not important & 7 & 13 & \\
\hline \multirow{2}{*}{$\begin{array}{l}\text { The existing Family Medicine undergraduate curriculum addresses leadership skills' } \\
\text { development }\end{array}$} & \multirow{2}{*}{$\begin{array}{l}\text { Yes } \\
\text { No }\end{array}$} & 7 & 20 & \multirow{2}{*}{0.28} \\
\hline & & 17 & 20 & \\
\hline \multirow{2}{*}{$\begin{array}{l}\text { The existing Family Medicine postgraduate curriculum addresses leadership skills } \\
\text { development }\end{array}$} & \multirow{2}{*}{$\begin{array}{l}\text { Yes } \\
\text { No }\end{array}$} & 11 & 27 & \multirow{2}{*}{0.30} \\
\hline & & 13 & 17 & \\
\hline \multirow{2}{*}{$\begin{array}{l}\text { Taking the specialty forward will require convincing all stakeholders including policy makers } \\
\text { and public at large. Do you think that it can be achieved if an effective leadership model is } \\
\text { developed and implemented? }\end{array}$} & \multirow{2}{*}{$\begin{array}{l}\text { Yes } \\
\text { No }\end{array}$} & 22 & 36 & \multirow{2}{*}{0.12} \\
\hline & & 02 & 8 & \\
\hline \multirow{2}{*}{$\begin{array}{l}\text { Reshaping health systems to ensure that they are primary care led will strengthen Family } \\
\text { Medicine. Do you think that Primary Care physicians should have leadership skills to take this } \\
\text { agenda forward? }\end{array}$} & Yes & 22 & 44 & \multirow[b]{2}{*}{-} \\
\hline & No & 2 & --- & \\
\hline Health systems decisions must be taken at the Primary Care level to ensure person- & Yes & 22 & 41 & \\
\hline Physicians should have leadership skills to take this agenda forward? & No & 2 & $3(7)$ & 1.00 \\
\hline Do you think that academic institutions of Family Medicine can play a leadership role in taking & Yes & 21 & 38 & $\$ 100$ \\
\hline the specialty forward? & No & 3 & 6 & 1.00 \\
\hline Do you think that practicing Family Physicians can play a leadership role in taking the & Yes & 24 & 40 & \\
\hline specialty forward? & No & --- & 4 & - \\
\hline
\end{tabular}

Chi square $p$-value.

${ }^{\$}$ Fisher exact test $\mathrm{p}$-value.

marketing skills for leaders.

FP's suggestions regarding strategies to market FM services are presented in Table 5. An equal proportion (54\%) of FPs that hold inleadership and non-leadership roles recommended that using social media (Facebook, Twitter) and appearing in media talk shows (58\%) are effective strategies for marketing purposes. In addition, the use of SMS and text services (in-leadership: 42\%, non-leadership: 48\%) can also be used to market FM services.

\section{Discussion}

According to our knowledge, this is the first study carried out in selected countries of the EMR to look at the respective leadership aspect of family medicine. We have documented the perceptions of family physicians with regards to effective family medicine leadership across the region.

As expected, study participants were divided with regards to 
Table 3: Recommendations of Family Physicians regarding different Leadership Models in the EMR.

\begin{tabular}{|c|c|c|c|}
\hline Questions & $\begin{array}{l}\text { In Leadership } \\
\text { Position } \\
\text { n=24 }\end{array}$ & $\begin{array}{c}\text { Not in leadership } \\
\text { position } \\
n=44\end{array}$ & ${ }^{*} p$-value \\
\hline $\begin{array}{l}\text { Proactive model: } \\
\text { UK model, health system in primary care and the GPs are in the driving seat with strong political commitment. } \\
\text { Comprehensive PHC (CPHC) concept with strong proactive approaches. Fits well with integrated and person- } \\
\text { centered care }\end{array}$ & $8.4(1.8)$ & $7.7(2.5)$ & 0.17 \\
\hline $\begin{array}{l}\text { Reactive model: } \\
\text { Usually applied in Lower and Middle Income countries (LMIC) countries where GPs are seen as second } \\
\text { professionals providing second quality service (poor healthcare for the poor people). This fits well with selective/ } \\
\text { basic (essential) PHC concept which works around 'care packages'. Weak on change and innovation; Job } \\
\text { Description based and nothing outside the box: fits well with disease model where hospitals are in control }\end{array}$ & $3.75(2.75)$ & $4.29(2.55)$ & 0.41 \\
\hline $\begin{array}{l}\text { Academic leadership model: } \\
\text { Used in the US and other European Union countries for years before Obama care; the focus is on } \\
\text { providing evidence. This fits well with nothing wrong / nothing right concept but wait until we see the evidence }\end{array}$ & $5.87(2.62)$ & $6.15(2.44)$ & 0.65 \\
\hline $\begin{array}{l}\text { Team leadership model: } \\
\text { Focus on practices and how can I be the best irrespective of what is happening in the rest of the health system. } \\
\text { This fits well with private PHC common in the Middle East }\end{array}$ & $4.37(2.37)$ & $6.06(2.66)$ & 0.01 \\
\hline $\begin{array}{l}\text { No model: } \\
\text { Just move with the wind and let me do my daily work approaches }\end{array}$ & $1.95(1.80)$ & $2.15(2.17)$ & 0.70 \\
\hline
\end{tabular}

Just move with the wind and let me do my daily work approaches

*Independent Sample T-test $P$ value.

Table 4: Skills required for effective leadership for FM in the EMR $(n=68)$.

\begin{tabular}{|c|c|c|c|}
\hline Questions & $\begin{array}{l}\text { In Leadership Position } \\
n=24\end{array}$ & $\begin{array}{l}\text { Not in leadership position } \\
n=44\end{array}$ & p-value \\
\hline \multicolumn{4}{|c|}{ The skills development needed to achieve effective leadership } \\
\hline Communication skills & 22 & 38 & $\$ 0.70$ \\
\hline People management skills & 12 & 31 & 0.09 \\
\hline Positive attitude development skills & 10 & 37 & 0.001 \\
\hline Planning and organizational skills & 20 & 34 & $\$ 0.75$ \\
\hline Team development and management skills & 18 & 34 & 0.83 \\
\hline Marketing skills & 5 & 27 & 0.001 \\
\hline Resource development and management skills & 15 & 30 & 0.63 \\
\hline Business/finance skills & 6 & 26 & 0.007 \\
\hline Dealing with failure & 13 & 30 & 0.25 \\
\hline Dealing with anger & 11 & 28 & 0.15 \\
\hline Dealing with unsatisfied clients & 10 & 27 & 0.12 \\
\hline Developing positive habits & 6 & 26 & 0.007 \\
\hline Language skills mastery & 2 & 28 & $\$<0.0001$ \\
\hline Public relations building & 13 & 27 & 0.56 \\
\hline Developing self-confidence & 12 & 32 & 0.06 \\
\hline Recognition and correction of deficiencies & 13 & 32 & 0.12 \\
\hline Recognition and strengthening of strengths & 11 & 30 & 0.07 \\
\hline Developing resilience, persistence Patience & 7 & 25 & 0.02 \\
\hline Organizational skills & 19 & 28 & 0.18 \\
\hline Change Management & 13 & 25 & 0.83 \\
\hline
\end{tabular}

Chi square $p$-value.

$\$$ Fisher exact test $\mathrm{p}$-value.

the current situation of family medicine in their countries. Those in leadership roles were more positive in this regard since their leadership position has an influence on their perception.It is important to notethe emerging consensus that leadership development in family medicine is needed for this region, as well as the rest of the world, in order for this specialty to progress [17]. Leadership development however, is not an easy task [18] and will require training, patience and resilience [19].

A mixed response was found with regards to family physicians currently being in a leadership role in health systems across the region. This is probably partially because of variability in the development of family medicine in the region. Again, a mixed response on the role played by family medicine leadership in bringing a favorable change in the EMR is not a surprise given the existing situation with regards to family practice in the region [1].

Respondents feel that establishing regional family medicine associations will enhance family practice and leadership roles in the specialty. This offers an opportunity for future improvement in 
Table 5: Perceptions of Family Physicians regarding strategies to market their services.

\begin{tabular}{|c|c|c|c|}
\hline Questions & $\begin{array}{l}\text { In Leadership Position } \\
n=24\end{array}$ & $\begin{array}{l}\text { Not in leadership position } \\
n=44\end{array}$ & p value \\
\hline \multicolumn{4}{|c|}{ Opportunities for Family Physicians to market their services } \\
\hline Providing good service to patients & 17 & 36 & 0.29 \\
\hline Appearing in talk shows on media & 14 & 26 & 0.95 \\
\hline Writing for print media & 8 & 21 & 0.25 \\
\hline Using social media such Facebook & 13 & 24 & 0.97 \\
\hline Using SMS/text messages & 10 & 21 & 0.63 \\
\hline Distributing promotion flyers & 7 & 19 & 0.25 \\
\hline Announcements at public places like mosques & 10 & 21 & 0.63 \\
\hline Hiring advertisement agencies & 5 & 16 & $\$ 0.27$ \\
\hline Conducting health awareness programs for public & 15 & 34 & 0.19 \\
\hline Holding open day/free camps & 9 & 26 & 0.08 \\
\hline Participating in exhibitions & 8 & 26 & 0.04 \\
\hline
\end{tabular}

Chi square $p$-value.

\$ Fisher exact test $\mathrm{p}$-value.

leadership development in the region. The majority of respondents were disappointed in the role of senior decision makers in health ministries with regards to capacity building within the specialty. This is perhaps more of a reflection of the current failure of family medicine leadership. It is already known that leadership developments will require partnership with stakeholders to have a favorable impact [20].

A majority of respondents believe that collaboration with international centers of excellence in support of leadership development in family practice is highly important. This could be through structured training courses in leadership development, mentoring and shadowing fellowship. This again offers an opportunity for future improvement in family medicine leadership development in the region and is an identified need [21].

Unfortunately, a mixed response was received with regards to the family medicine curriculum addressing leadership skills. This area is perhaps most critical to address shortcomings in leadership development in the region, and this need has already been identified in other regions [22-24]. The role of the doctor in advocating change in healthcare is well documented [25].

A strong need was felt with regards to the involvement of policy makers and the public at large with regards to effective leadership development in family medicine, which would require existing leaders to play a more convincing role. It was strongly felt that family physicians should have leadership skills to strengthen health systems by ensuring that it isprimary care-led. This will require leadership skills of the highest order, as it would involve convincing existing policy makers about the benefits of such an approach that has as has given favorable results in several countries including developing countries such as Cuba [26].

It was strongly felt that decisions on health systems should be made at the primary care level and family physicians should have leadership skills fortheir implementation. Based on this response, it is important to consider the reality that consensus between leadership at all levels of health care is crucial to expect positive health-related outcomes. Such a strategy is likely to lead to successful outcomes [27].
There was a general agreement that academic institutions and practicing family physicians can play a leadership role in taking the specialty forward. Hence, leadership development should be focused at both of these levels $[13,14]$.

Developing leadership models is important for overall leadership in family practice. The highest mean scores were obtained for the proactive model, followed by academic and team leadership models. It is no surprise that the lowest support was found when family physicians were asked if they feel no leadership model is required to take FM forward. It is important to consider the fact that different leadership models are required for various task accomplishments, and therefore overall leadership development in family practice should focus on core leadership competencies rather than only focus entirely leadership models $[27,28]$.

According to respondents, skills required for effective leadership in family practice included traditional skills such as communication and people management skills. Respondents also advocated other skills such as business and financial management, marketing, and resource management, which are traditionally neglected in training programs. There is an additional need toinclude skills related to e-technology as part of leadership development [29].

It is important that the family physician of the future also has skills to deal with change management, resilience development, building public relations, and dealing with failure and anger. Developing self-confidence, positive habits, team development, and management skills are also supported by respondents as necessary skills for the family physician of future. Recognizing deficiencies and subsequent correction, as well as identifying strengths and their future development, were considered skills that family physicians should possess. Family medicine is rapidly developing in the region. This is a critical time where leadership could play important role to nurture the future generation [30].

There is evidence to suggest that robust leadership skills are mandatory for successful leadership initiatives in any discipline $[18,19,31]$. Leadership of organizations needs to be consistent in terms 
of leadership styles and behaviors; in developing shared leadership across the organization; in embodying the vision and values of the organization; in ensuring shared and consistent approaches to performance management; in practicing compassion as a cultural value in all relationships within the organization; in encouraging, facilitating, and rewarding learning, quality improvement and innovation; and in developing team, inter-team and cross-boundary working within and across organizations in health and in social care. Leaders must also work together to build cultures where the success of overall patient care is every leader's priority, not just the success of their individual areas of responsibility [7].

Respondent's views on opportunities for family physicians to market their services also show interesting awareness among them with regards to this neglected aspect of their professional life. General support was found for strategies such as providing good service to patients, appearing on talk shows, writing for print media, distributing flyers, and conducting health awareness sessions. The use of social media and texting were also found as tools to market services. It is very encouraging to see respondents being cognizant of marketing strategies and their importance in today's world of intense competition.

Some differences in opinion have been noted between family physicians that are in a leadership position compared to those who are not. They are not substantial and are largely due to the leadership position that family physicians are in, having a more favorable view of existing leadership model.

\section{Conclusion}

Despite many obstacles, the last three decades showed tremendous progress in the development and recognition of family medicine as a specialty through the region. Now is the time to move away from traditional models of leadership and incorporate areas that are considered essential for successful leadership initiatives in today's fast changing world. It is going to be the future leaders in family medicine that will shape the specialty in the near future.

Leadership development is the keyto success of any business. Family medicine as a specialty worldwide and in the East Mediterranean Region needs to succeed in addressing the health and healthcare needs of the population, where leadership is needed now more than ever. Such leaders should focus on undergraduate and postgraduate development as well as maintain the standard of the specialty and its standing within communities. The Future of Family Medicine clearly indicates that now is a time of change to transform and renew the specialty of family medicine to meet the needs of people and society in a changing environment [9]. We are pledging to develop a "New Leadership Model for Family Physicians" in the East Mediterranean Region. International collaboration is essential and structured training is the way forward.

If leadership is about any single concept, it is about change. Science, medical education, health care delivery, and the needs of society do not remain static. We, as family physicians, must be at the forefront of change. Through our leaders, we must position family medicine to show the way to tomorrow's health care [30].

\section{Authors" Contributions}

WG, SR, TK and NK have designed the study and the questionnaire. WG and NK administrated and manged the survey through all its stages. All authors have contributed to the analysis and writing pf the manuscript. SR, WG, TK and AS have finalised the final submission. All authors read and approved the manuscript.

\section{Disclaimer}

This article presents independent research <commissioned by/ supported by/ in part funded by the National Institute for Health Research (NIHR) under the Collaborations for Leadership in Applied Health Research and Care (CLAHRC) programme for North West London. The views expressed in this publication are those of the author(s) and not necessarily those of the NHS, the NIHR or the Department of Health.

\section{References}

1. Mourshed M, Hediger V, Lambert T. Gulf Cooperation Council Health Care: Challenges and Opportunities. McKinsey \& Company. 2016.

2. World Health Organization. Primary Health Care: Now More Than Ever. World Health Report 2008. WHO: Geneva, 2008.

3. Al-Shebri AMA, KhojaT. Doctors and Leadership of health care organizations (Editorial). Saudi Med J. 2009; 30: 1253-1255.

4. Al-Shebri AMA. Is there a need to involve doctors in management of healthcare in Saudi Arabia. Saudi Medi J. 2003; 24: 1165-1167.

5. Berwik DM. Eleven worthy aims for clinical leadership of health system reforms. JAMA. 1994; 272: 797-802.

6. Qidwai W. Addressing healthcare challenges in Pakistan: issues, possible remedies and way forward. J Dow Uni Health Sci. 2016; 10: 41-42.

7. West MA, Armit K, Loewenthal L, Eckert R, West T, Lee A. Leadership and Leadership Development in Health Care: The Evidence Base. London, FMLM/The King's Fund/CCL, 2015.

8. Qidwai W. Leadership in Healthcare is a neglected issue: A call for action (editorial). JLUMHS. 2014; 13: 49-50.

9. Wender R, Borkan J, Davis A; Association Of Departments Of Family Medicine. A pivotal time for family medicine leadership development. Ann Fam Med. 2011; 9: 182

10. Grady CM. Can complexity science inform physician leadership development? Leadersh Health Serv. 2016; 29: 251-263.

11. Jefferies $\mathrm{R}$, Sheriff $\mathrm{IH}$, Matthews $\mathrm{JH}$, et al. Leadership and management in UK medical school curricula. J Health Organ Manag. 2016. 30: 1081-1104.

12. Farver CF, Smalling S, Stoller JK. Developing leadership competencies among medical trainees: five-year experience at the Cleveland Clinic with a chief residents' training course. Australas Psychiatry. 2016; 24: 499-505.

13. White $D$, Krueger $P$, Meaney $C$, et al. Identifying potential academic leaders: Predictors of willingness to undertake leadership roles in an academic department of family medicine.Can Fam Physician. 2016; 62: e102-109.

14. Vickery KD, Rindfleisch K, Benson J, et al. Preparing the Next Generation of Family Physicians to Improve Population Health: A CERA Study. Fam Med. 2015; 47: 782-788.

15. Qidwai W. Increasing Health Care Costs and its Adverse Impact on Healthcare and Health: A Call for Action. JLUMHS. 2013; 12: 68-69.

16. Qidwai W, Beasley JW, Francisco JGC, et al. The present status and future role of Family Doctors: a perspective from International Federation of Primary Care Research Networks. Primary Health Care Research and Development. 2008; 9: 172-182.

17. Puffer JC, Borkan J, DeVoe JE,, et al. Envisioning a New Health Care System for America. Fam Med. 2015; 47: 598-603.

18. Robinson MA. Leadership takes courage. Alta RN. 2016; 72: 46.

19. McNeil George. "Resilience and leadership for the challenges ahead". Pharos Alpha Omega Alpha Honor Med Soc. 2016; 79: 54-55. 
20. Pullen C. A Powerful New Partnership to Build Leadership Capacity in Healthcare in Canada. Nurs Leadersh (Tor Ont). 2016; 29: 31-33.

21. Rosser E, Scammell J, Bevan A, Hundley VA. Strong leadership: the case for global connections. J Clin Nurs. 2016; Accepted Author Manuscript. doi:10.1111/jocn.13562.

22. Maddalena $\mathrm{V}$. Leadership training for undergraduate medical students Leadersh Health Serv (BradfEngl). 2016; 29: 348-351.

23. Jefferies $\mathrm{R}$, Sheriff $\mathrm{IH}$, Matthews $\mathrm{JH}$, et al. Leadership and management in UK medical school curricula. J Health Organ Manag. 2016; 30: 1081-1104.

24. Ofner D. Leadership and training. Eur Surg. 2016; 48: 163-165.

25. Smits SJ, Bowden DE, Wells JO. The role of the physician in transforming the culture of healthcare. Leadersh Health Serv (BradfEngl). 2016; 29: 300-312.

26. Qidwai W. Healthcare Delivery System Improvements: A Way Forward to Improve Health in Developing Countries and Pakistan. J Coll of Physicians Surg Pak. 2013: 23: 313-314.
27. Menaker R. Leadership Strategies: Achieving Personal and Professional Success. J Med Pract Manage. 2016; 31: 336-339.

28. Morgan C. How to Lead in Today's Changing Healthcare Landscape. Fla Nurse. 2016; 64: 14

29. Keijser W, Smits J, Penterman L, Wilderom C. Physician leadership in e-health? A systematic literature review. Leadersh Health Serv (BradfEngl). 2016; 29: 331-347.

30. Taylor RB. The promise of family medicine: history, leadership, and the Age of Aquarius. J Am Board Fam Med. 2006;19: 183-190.

31. Deschamps C, Rinfret N, Lagacé MC, Privé C. Transformational Leadership and Change: How Leaders Influence Their Followers' Motivation Through Organizational Justice. J Healthc Manag. 2016; 61: 194-213.
J Fam Med - Volume 4 Issue 2 - 2017

ISSN : 2380-0658 | www.austinpublishinggroup.com Swaka et al. (C) All rights are reserved
Citation: Rawaf S, Qidwai W, Khoja TAM, Nanji K, Kurashi NY and Alnasir F, et al. New Leadership Model for Family Physicians in the Eastern Mediterranean Region: A Pilot Study Across Selected Countries. J Fam Med. 2017; 4(2): 1107. 